\title{
Improved Predictive Model to the Cross-Sectional Resistance of CFT
}

\author{
Iman Mansouri ${ }^{1}$, Rolando Chacón ${ }^{2}$ and Jong Wan $\mathrm{Hu}^{3,4^{*}}$ \\ ${ }^{1}$ Dept. of Civil Eng., Birjand University of Technology, P.O. Box 97175-569, Birjand, Iran E-mail: mansouri@birjandut.ac.ir \\ ${ }^{2}$ Construction Eng. Dept., Polytechnic University of Catalonia, Barcelona, Spain, E-mail: rolando.chacon@upc.edu \\ $3^{3 *}$ Department of Civil and Environmental Engineering, Incheon National University, 12-1 Songdo-dong, Yeonsu-gu, Incheon 406-840, South \\ Korea (corresponding author)
}

(Manuscript Received 000 0, 2009; Revised 000 0, 2009; Accepted 000 0, 2009) -please leave blank

\begin{abstract}
This paper proposes improved a theoretical prediction equation for concrete-filled steel tubes (CFT) subjected to compressive forces. This ultimate load capacity is inferred from a database of 344 experimental results reported in the literature by using Gene Expression Programming (GEP). Moreover, a series of structural comparisons between design provisions, other mechanically-derived expressions and the proposed prediction are addressed. The levels of accuracy, practical use and phenomenological understanding of the phenomenon are pinpointed. The results obtained are in good agreement with both the experimental and theoretical predictions. Advantageously, the proposed expressions are robust and provide an accurate prediction. Disadvantageously, the expression does not expl, elyt, Advantages and disadvantages of such type of predictions are pinpointed.
\end{abstract}

Keywords: Concrete-filled tubes; CFT; Gene expression programming; GEP

\section{Introduction}

Concrete-filled tubes (CFT) are extensively used in structural engineering and including a steel tube with a concrete core casted inside. Usages of CFT range from high-rise buildings to bridges construction. For the past, CFT are usually designed as slender with high length-to-diameter ratios ( $L / D>15.0$ prone overall buckling) whereas for the latter, these structural elements are generally designed as stocky ( $L / D<10.0$ not prone to overall buckling).

One key parameter which determines the crosssectional resistance CFT is the steel contribution ratio $\delta$, defined in Eq. (1). The cross-sectional resistance $N_{p l}$ for circular CFT (pure compression) is generally defined as in Eq. (2) in which the coefficients $\alpha$ and $\beta$ account for the passive confinement provided by the steel tube to the concrete core. The passive confinement is particularly effective in stocky columns (i.e., members not prone to overall buckling $L / D<10$ ). Researchers have provided different expressions for accurately defining those coefficients as a function of geometry $\left(A_{s}, A_{c}\right)$ and material parameters $\left(f_{y}, f_{c k}\right)$ [1-3]. In some cases, empirical calibrations have been also used [4] for adjusting the results obtained to the experimental or numerical data found in vast experimental databases publicly available in the literature $[5,6]$.

$$
\begin{gathered}
\delta=\frac{A_{s} f_{y}}{A_{s} f_{y}+A_{c} f_{c k}} \\
N_{p l}=\alpha A_{c} f_{c k}+\beta A_{s} f_{y}
\end{gathered}
$$

\footnotetext{
${ }^{\dagger}$ This paper was recommended for publication in revised form by Associate Editor 000000 -please leave blank.

*Corresponding author. Tel.: +82 please fill in, Fax.: +82 please fill in

E-mail address: please_fill_in@email.ac.kr.

(C) KSME \& Springer 2010
} 
The past decade has seen a growth in attempts to employed CFT columns in structural engineering problems. Recently, cyclic loading tests on CFT columns have been performed by Zhou and $\mathrm{Xu}$ [7]. They concluded that the axial compressive force level and thickness of outer tubes have an elementary influence on the behavior of the test specimens while the hollow ratio and the concrete strength have a little influence when the axial compressive force level is low. Kim et al. [8] studied the CFT connections experimentally to improve the design of their structural details. Also, Hu and Hwang [9] investigated the performance of new composite (steelconcrete) moment connections through numerical simulations. Hu and Leon [10] evaluated the seismic performance and evaluation for composite-moment frames (C-MF) with a new type of bolted connections. The application of shape memory alloys in CFT columns has been studied by Hu et al. [11]. Also, Hu et al. [12] suggested a design procedure based on the advanced methods introduced in the AISC Provisions.

Moreover, in last decades, various algorithms aimed at predicting the relationships between set of variables from a set of data have [13-15]. Gene expression programming (GEP) is a learning evolutionary algorithm capable of acquiring a level of understanding the existing relationships between variables in sets of data. Subsequently, these relationships are explained through robust yet simple models. Gene Expression Programming can be used in a vast array of domains ranging from conventional mathematical models to neural networks. Similarly, a widely used technique in the formulation development is the Artificial Neural Network (ANN) approach. Both methods (GEP and ANN) are capable of establishing subtle and nonlinear relationships within the data, with no requirement used-defined functional forms that should be used. GEP generates relatively simple equations characterizing the relationships that could be interpreted directly [16] whereas ANN use black boxes and provided a reduced phenomenological insight into the key relationships between parameters. Various examples on the application of GEP techniques as predictive tools based upon complex relationships between parameters and experimental data sets are available [17-19] .

In this paper, two GEP models for predicting the cross-sectional resistance of CFT are provided. The mathematical models are simple yet robust. The results obtained are derived from databases found in the literature [5, 6] and fits accurately the experimental results as well as the studied analytical predictions.

\section{Review of the earlier work}

\subsection{Concrete-filled circular tubes subjected to axial loading}

In pure compression, the mechanical base that underpins the cross-sectional strength of CFT is the passive confinement provided by the steel tube to the concrete core. The mechanical behavior of short stub CFT was first characterized in [20, 21]. Ever since that, the basic keys have motivated researchers in defining more refined quantitative predictions of the cross-sectional strength of CFT. Fig. 1 illustrates schematically this basic mechanical key. Considering that both materials present a different Poisson coefficient, the lateral expansion of both bodies vary when under stresses along the longitudinal direction. 


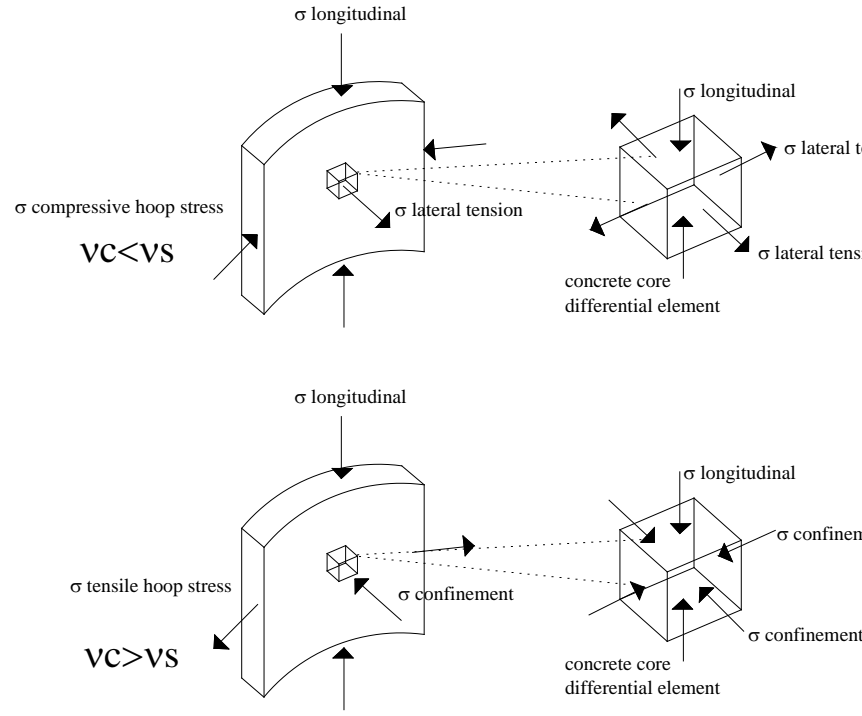

Fig. 1. Mechanical principle for the cross-sectional resistance (compression).

In the preliminary step of a hypothetical monotonically increasing load applied concentrically on a CFT cross-section, the steel tube extends faster in the radial direction than the concrete core, i.e., the steel tube does not provide any strength to the concrete. Compressive hoop stresses are established in the steel tube and lateral tensile stresses in the concrete core (Fig. $1 v_{\mathrm{c}}<v_{\mathrm{s}}$ ). The lateral tension on the concrete produces micro cracking which affects the Poisson coefficient and the entire stiffness of the body. At several points, the lateral development of the concrete core catches up the steel tube and the steel tube begins providing a lateral restraint (Fig.1 $\left.v_{\mathrm{c}}>v_{\mathrm{s}}\right)$. The hoop stresses in the steel become tensile and from this point onwards, the steel is under biaxial stresses (compressive and tensile) whiles the concrete core is under triaxial compressive stresses.

As formerly stated, CFT provide a greater crosssectional strength than the simple case in which the contributions of steel and concrete are computed separately. This increment in capacity is because of the significant confinement influence given by the steel tube to the concrete core. The passive confinement the steel tube provides to the concrete core is sectional capacity of the CFT. This influence has been studied considerably but this is still a matter of debate among researchers that have proposed mechanically-derived design expressions.

The passive confinement has been mostly investigated in concentrically compressed CFT. Researchers have newly provided various alternatives for obtaining $\alpha$ and $\beta$ from Eq. (1) as a function of the cross-sectional geometry [1-4], i.e., the diameter $D$, the thickness of the tube $t$, and the nominal strengths of the materials $f_{c k}$ and $f_{y}$. These suggestions have been statistically evaluated (and thoroughly described) in previous studies [22, 23] by comparing their own test results with the corresponding theoretical strengths and those included in structural codes. These authors pointed out that the ultimate load strengths suggested in [1-3] follow mechanically derived models coupled including some empiricallyobtained coefficients for the sake of calibration. Furthermore, comparisons between these suggestions and 344 experimental tests found in [5, 6] were performed recently [4]. It was concluded that the predictions given in [1] provide the most statistically and structurally sound results among those studied. It is significant to point out that in the experimental dataset used for drawing these conclusions, the $L / D$ and $D / t$ ratios of the tests were selected in such a way that no local/overall buckling was expected to happen as the preliminary failure mode. In some works [24, 25], the load-bearing capacity and ductility of stocky CFT are investigated experimentally, numerically, analytically and also from the structural codes perspective. Comparisons between relevant codes and experimental/numerical results 
are completely carried out. Numerical and experimental studies related to this topic are incessantly refined with more models, predictions and details of the formulations [26]. A plenary summary of several design codes and the cross-sectional strength of CFT is provided in [27].

\subsection{Gene Expression Programming}

The Genetic Programming (GEP) methodology was first proposed by Koza [28], as a generalization of Genetic Algorithms (GAs) [29] . The superiority of a system like GEP are obvious from essence, but the most important are (1) the chromosomes are plain entities: linear, compact, relatively small, easy to manage genetically (repeat, mutate, recombine, etc.); (2) the expression trees are particularly the expression of their relative chromosomes; they are quality upon which selection acts, and based on fitness, they are chosen to duplicate with amendment. Generally, there are two main players in GEP: the chromosomes and the expression trees (ETs), the second including the expression of the genetic data encoded in the past. The procedure of information decoding (from the chromosomes to the expression trees) is named translation; and this translation points obviously a type of code and a set of rules. The genetic code is really easy: a one-to-one relationship between the symbols of the chromosome and the functions and terminals they represent [13] .

A GEP individual contains various genes where each gene includes the same number of nodes Furthermore, each gene is divided in two parts: the head and the tail of the gene. The head can include terminal and functional nodes, while the tail can include only terminal nodes. While the head size is mostly suggested as a variable of the algorithm, the tail size is calculated as $t=h^{*}\left(n_{\max }-1\right)+1$, where $h$ denotes the head size and $n_{\max }$ the maximum number of children per function node [30]. More details about GEP can be found in Ref. [28].

\section{EN1994}

EN1994 [31] provides with guidelines for the design of composite columns and compression members with steel grades S235 to S460 and normal weight concrete of strength classes C20/25 to C50/60. These guidelines apply to isolated columns and columns in framed structures where the other structural members are either composite or purely metallic. The steel contribution ratio $\delta$ (Eq. 1) should fulfill the condition $0,2 \leq \delta \leq 0,9$. The members must be checked for: resistance of the member, resistance to local buckling and resistance to shear between steel and concrete elements.

When it comes to cross-sectional resistance, two methods of design are given: i) a general method whose scope includes member with non-symmetrical or non-uniform cross-sections over the length, ii) a simplified method for members of doubly symmetrical cross-sections. With the latter, the plastic resistance to compression $N_{p l, R d}$ of a CFT cross-section should be calculated by adding the plastic resistances of its components. Account may be taken of increase in strength of concrete caused by confinement. These increment may be added for members subjected to axial load with low load eccentricity $(e / D \leq 0,1)$ according to Eq. (3) to (8):

$$
N_{p l, R d}=n_{a} A_{a} f_{y d}+A_{c} f_{c d}\left(1+n_{c} \frac{t f_{y}}{D f_{c k}}\right)
$$

where,

$$
n_{a}=n_{a o}+\left(1-n_{a o}\right)(10 e / D)
$$




$$
\begin{gathered}
n_{c}=n_{c o}(1-10 \mathrm{e} / \mathrm{D}) \\
n_{a o}=0,25(3+2 \bar{\lambda}) \quad n_{a o} \leq 1.0 \\
n_{c o}=4.9-18.5 \bar{\lambda}+17 \bar{\lambda}^{2} \quad n_{c o} \geq 1.0 \\
\bar{\lambda}=\sqrt{\frac{N_{p l}}{N_{c r}}}
\end{gathered}
$$

\section{Experimental database}

Vast databases of thousands of experimental tests are available in continuously updating webpages and wikis by researchers in UK [5] and USA [6]. These databases include tests performed by several authors and provide geometrical, material and ultimate loads information of circular, square and rectangular CFT subjected to axial and/or flexural loads. In this paper, a sample of 344 experimental circular CFT subjected to pure compression is used for comparison purposes. The sample is chosen in such a way the specimens are not prone to global or local buckling according to the EN1994 criteria. Figs. 2 to 6 display the ratios $N_{P l, \text { experimental }} N_{\text {pl,theoretical }}$ as a function of $\delta$, the steel contribution ratio for different predicting models.

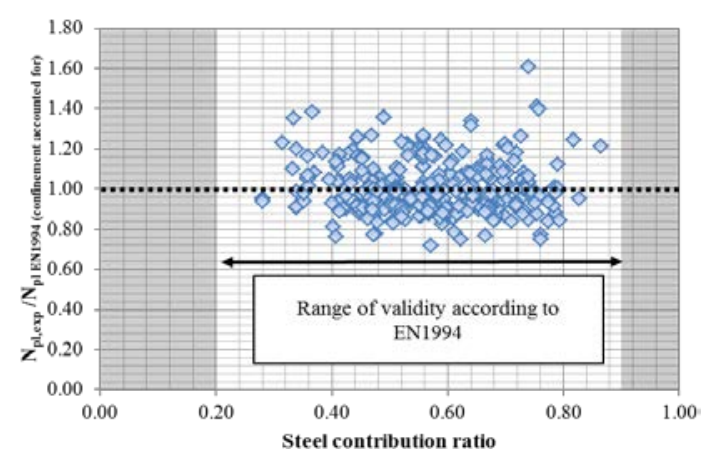

Fig. 2. Experimental results vs. EN1994 prediction (confinement of the concrete accounted for)

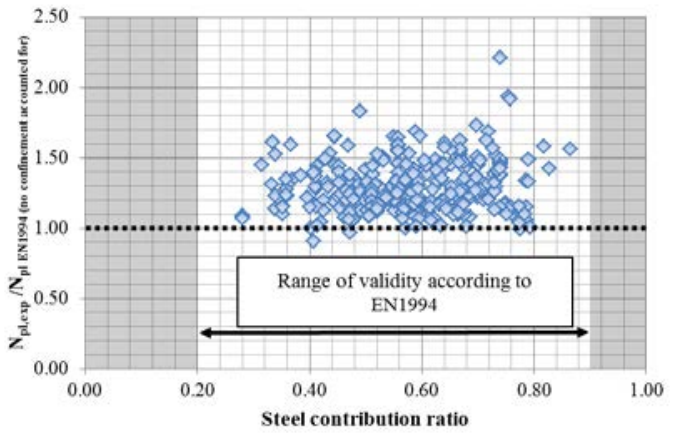

Fig. 3. Experimental results vs. EN1994 prediction (no confinement accounted for)

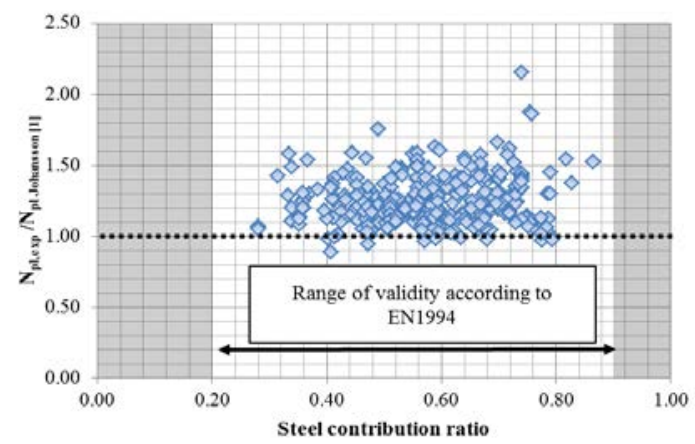

Fig. 4. Experimental results vs. prediction provided in Ref. [1]

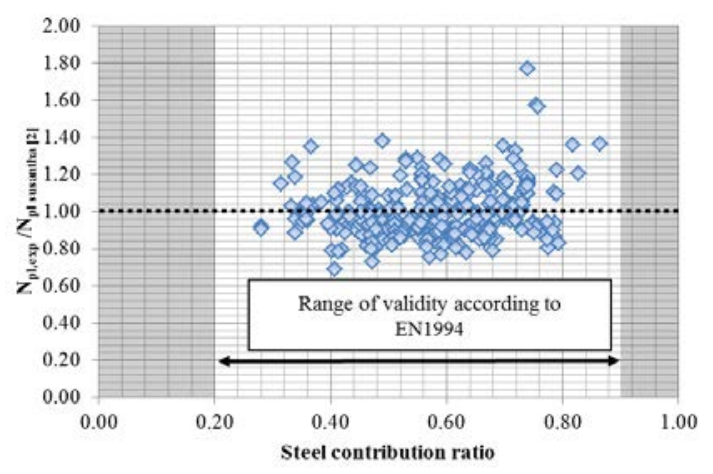

Fig. 5. Experimental results vs. prediction provided in Ref. [2]

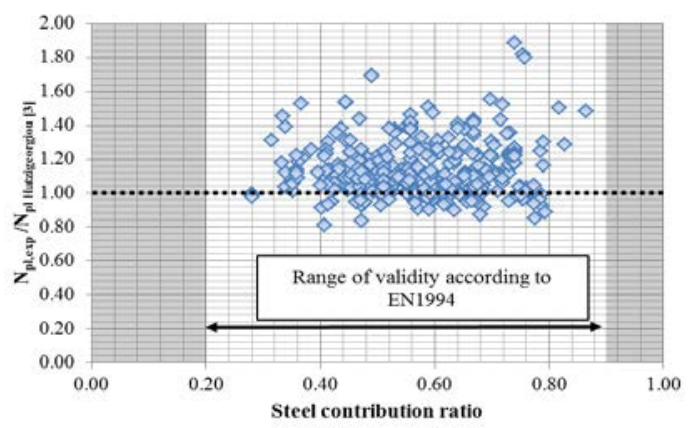

Fig. 6. Experimental results vs. prediction provided in Ref. [3] 
Table 1 shows a summary of the proposed expresions $\mathrm{F}_{\text {Joh }}, \mathrm{F}_{\text {Sus }}$, and $\mathrm{F}_{\mathrm{Hat}}$ found in [1][2][3], respectively. In all cases, the ultimate load capacity prediction includes explicitly the passive confinement of the concrete core via different approaches with a form similar to the generic expression (2).

Table 1 . Summary of the expressions

\begin{tabular}{|c|c|}
\hline [1] & $\begin{array}{l}\mathrm{F}_{\mathrm{Joh}}=\mathrm{A}_{\mathrm{c}} \cdot \mathrm{f}_{\mathrm{cc}}+\mathrm{A}_{\mathrm{s}} \cdot \sigma_{\mathrm{al}} \\
\varepsilon_{\mathrm{ahr}}=\frac{\varepsilon_{\mathrm{v}} \cdot\left(v_{\mathrm{s}}-v_{\mathrm{c}}\right)}{\left[1+\frac{2 \cdot \mathrm{t} \cdot \mathrm{E}_{\mathrm{s}}}{(\mathrm{D}-2 \cdot \mathrm{t}) \mathrm{E}_{\mathrm{c}}}\right]} \\
\varepsilon_{\mathrm{ah}}=\varepsilon_{\mathrm{ahr}}-v_{\mathrm{s}} \cdot \varepsilon_{\mathrm{v}} \\
\sigma_{a h}=\frac{E_{\mathrm{s}}}{1-v_{\mathrm{s}}^{2}} \cdot\left(\varepsilon_{a h}+v_{\mathrm{s}} \cdot \varepsilon_{a l}\right) \\
\sigma_{a l}=\frac{E_{\mathrm{s}}}{1-v_{\mathrm{s}}^{2}} \cdot\left(\varepsilon_{v}+v_{\mathrm{s}} \cdot \varepsilon_{a h}\right) \\
\sigma_{\mathrm{lat}}=\sigma_{\mathrm{ah}} \frac{2 \cdot \mathrm{t}}{(\mathrm{D}-2 \cdot \mathrm{t})} \\
\mathrm{k}=1,25 \cdot\left(1+0,062 \cdot \frac{\sigma_{\mathrm{lat}}}{\mathrm{f}_{\mathrm{ck}}}\right) \cdot \mathrm{f}_{\mathrm{ck}}^{-0,21} \\
\mathrm{f}_{\mathrm{cc}}=\mathrm{f}_{\mathrm{ck}} \cdot\left(\frac{\sigma_{\mathrm{lat}}}{\mathrm{f}_{\mathrm{tk}}}+1\right)^{\mathrm{k}} \\
v_{\mathrm{s}}=0,3 ; v_{\mathrm{c}}=0,2 ; \varepsilon_{\mathrm{al}}=\varepsilon_{\mathrm{v}}=0,002\end{array}$ \\
\hline [2] & $\begin{array}{l}\mathrm{F}_{\text {Sus }}=\mathrm{A}_{\mathrm{c}} \cdot \mathrm{f}_{\mathrm{cc}}+\mathrm{A}_{\mathrm{s}} \cdot \mathrm{f}_{\mathrm{y}} \\
\beta=v_{\mathrm{c}}-v_{\mathrm{s}} \\
v_{\mathrm{c}}^{\prime}=\frac{0,881}{10^{6}} \cdot\left(\frac{\mathrm{D}}{\mathrm{t}}\right)^{3}-\frac{2,58}{10^{4}} \cdot\left(\frac{\mathrm{D}}{\mathrm{t}}\right)^{2}+\frac{1,953}{10^{2}} \cdot\left(\frac{\mathrm{D}}{\mathrm{t}}\right)+0,4011 \\
v_{\mathrm{c}}=0,2312+0,3582 \cdot v_{\mathrm{c}}^{\prime}-0,1524 \cdot\left(\frac{\mathrm{f}_{\mathrm{ck}}}{\mathrm{f}_{\mathrm{y}}}\right)+4,843 \cdot v_{\mathrm{c}}^{\prime} \cdot\left(\frac{\mathrm{f}_{\mathrm{ck}}^{\prime}}{\mathrm{f}_{\mathrm{y}}}\right)-9,169 \cdot\left(\frac{\mathrm{f}_{\mathrm{ck}}}{\mathrm{f}_{\mathrm{y}}}\right)^{2} \\
\mathrm{f}_{\mathrm{rp}}=\beta \cdot \frac{2 \cdot \mathrm{t}}{\mathrm{D}-2 \cdot \mathrm{t}} \cdot \mathrm{f}_{\mathrm{y}} \\
\mathrm{f}_{\mathrm{cc}}=\mathrm{f}_{\mathrm{ck}}+4 \cdot \mathrm{f}_{\mathrm{rp}}\end{array}$ \\
\hline [3] & $\begin{array}{l}\mathrm{F}_{\text {Hat }}=\mathrm{A}_{\mathrm{c}} \cdot \mathrm{f}_{\mathrm{cc}}+\mathrm{A}_{\mathrm{s}} \cdot \mathrm{f}_{\mathrm{yc}} \\
\sigma_{\mathrm{h}}=\mathrm{f}_{\mathrm{y}} \cdot \exp \left(\ln \left(\frac{\mathrm{D}}{\mathrm{t}}\right)+\ln \left(\mathrm{f}_{\mathrm{y}}\right)-11\right) \\
\mathrm{f}_{\mathrm{rp}}=\frac{2 \cdot \sigma_{\mathrm{h}} \cdot \mathrm{t}}{\mathrm{D}-2 \cdot \mathrm{t}} \\
\mathrm{f}_{\mathrm{cc}}=\mathrm{f}_{\mathrm{ck}}+4,3 \cdot \mathrm{f}_{\mathrm{rp}} \\
\mathrm{f}_{\mathrm{yc}}=0,5 \cdot\left(\sigma_{\mathrm{h}}-\sqrt{4 \cdot \mathrm{f}_{\mathrm{y}}^{2}-3 \cdot \sigma_{\mathrm{h}}^{2}}\right)\end{array}$ \\
\hline
\end{tabular}

\section{Application of GEP for the prediction of $N_{p l}$ in} stocky CFT

There are five major steps in preparing to use GEP, of which the first is to choose the fitness function [32]. The fitness of an individual program $i$ for fitness case $j$ is evaluated as in Eq. (9):

if $E(i j) \leq p$, then $f_{(i j)}=1$; else $f_{(i j)}=0$

in which $p$ is the accuracy and $E(i j)$ is the error of an individual program $i$ for fitness case $j$. For the absolute error it is expressed by Eq. (10):

$E_{(i j)}=\left|P_{(i j)}-T_{j}\right|$

Again for the absolute error, the fitness $f_{i}$ of an individual program is expressed by Eq. (11):

$f_{i}=\sum_{j=1}^{n}\left(R-\left|P_{(i j)}-T_{j}\right|\right)$

where $R$ is the selection range, $P_{(i j)}$ is the value predicted by the individual program $i$ for fitness case $j$ (out of $n$ fitness cases), and $T_{j}$ is the target value for fitness case $j$. So, for a perfect fit, $P_{(i j)}=T_{j}$ for all fitness cases and maximum fitness $f_{\max }=R_{n}$, where $n$ is the number of fitness cases.

The second major step includes of choosing the set of terminals $N_{p l}$ and the set of functions $F$ to create the chromosomes. In this problem, the terminal set consists of the independent variables associated with the material and the cross-sectional properties of CFT, i.e., $N_{p l}=f\left(D, t, f_{y}, f_{c k}\right)$.

The third major step is to select the chromosomal architecture, i.e., the length of the head and the number of genes. A head length $h=8$, and three genes per chromosome were employed. 
The fourth major step is to choose the linking function. In this study, the sub-ETs were linked by addition. Finally, the set of genetic operators that cause variation and their rates are chosen.

From the collected data sets used in this study, around $75 \%$ of data were used for training (chosen randomly until the best calibration performance was obtained), while the remaining patterns (25\%) were used for testing, or validating, the model. The GEP-based explicit formulation of $N_{p l}$ is in the Eq. (12):

$$
N_{p l}=\left(f_{c k}{ }^{\left[\frac{t f y}{87,38 D}\right]}\right)\left(\ln \left[\frac{f_{c k}{ }^{2} t f_{y}}{\ln \left(f_{y}\right)}\right]\right)\left(\frac{D^{2}}{320}\right)
$$

in which the following consistent units must be used: $D=$ diameter of the tube $(\mathrm{mm}), t=$ thickness of the tube $(\mathrm{mm}), f_{y}=$ yield strength of the steel $(\mathrm{MPa})$, $f_{c k}=$ concrete compressive strength $(\mathrm{MPa})$, $N_{p l}=$ ultimate load $(\mathrm{kN})$.

$N_{p l}=\frac{1}{1.015}\left(\sinh \left(\frac{N_{p l, R d}}{662883.188}\right)+\sqrt{N_{p l, R d}}-9.995\right)(13)$

where the $N_{p l, R d}$ obtains from Eq. (3) and the unit for both $N_{p l}$ and $N_{p l, R d}$ is Newton in Eq. (13).

\section{Results}

The material and geometrical cross-sectional characteristics, namely, $D, t, f_{y}$ and $f_{c k}$ reported for the experimental data were used as inputs to the program. GEP model was developed according to experimental data. Table 2 summarizes key statistical features of the results obtained for the different theoretical predictions depicted previous sections. It is worth pointing out that the theoretical prediction provided by EN1994 when confinement of the con- crete is accounted for exceeds in most cases the experimentally obtained values. In the case of predictions proposed by researchers [1-3], the results provided by Johansson fit adequately to the experimental values with a low percentages of specimens exceeding the experimentally obtained ultimate axial load.

Table 2. Statistical summary ( $\left.N_{p l, \text { experimental }} / N_{p l, \text { theoretical predictions }}\right)$

\begin{tabular}{l|l|l|l|l|l}
\hline Parameter & EN1994-Conf & EN1994-No Conf & {$[1]$} & {$[2]$} & {$[3$} \\
\hline Allean & 1.00 & 1.29 & 1.25 & 1.00 & 1. \\
\hline Standard Var. & 0.13 & 0.18 & 0.17 & 0.15 & 0. \\
\hline Variation & 0.13 & 0.14 & 0.14 & 0.15 & 0. \\
\hline \% Unsafe & $56.98 \%$ & $1.16 \%$ & $2.91 \%$ & $60.17 \%$ & 18 \\
\hline
\end{tabular}

a model gives $R>0.8$, and the errors are at the minimum, there is a strong correlation between the predicted and measured values [17]. The model can therefore be judged as satisfactory. The correlation coefficient (Eq.(14)) illustrates the fit of the GEP's output parameter approximation curve to the actual data output parameter curve.

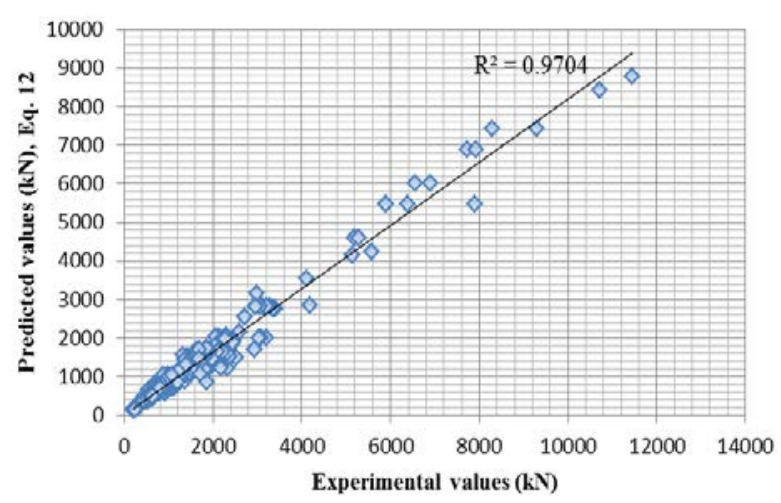

Fig. 7. Experimental vs. predicted values in absolute terms for Eq. (12). 


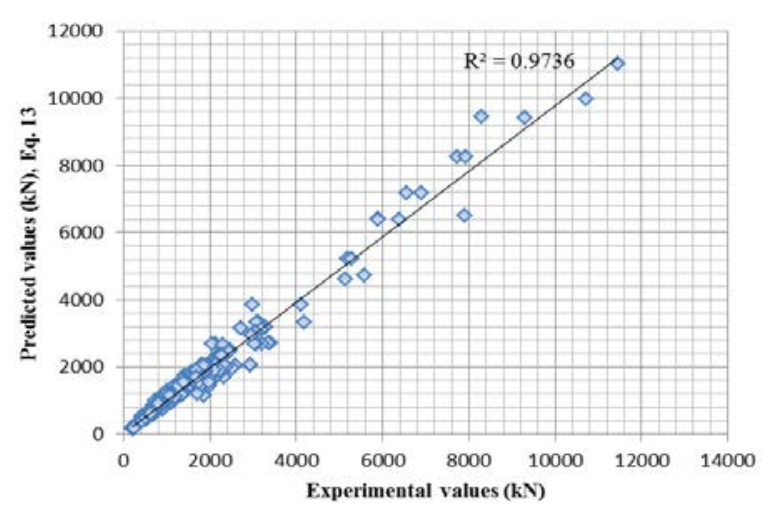

Fig. 8. Experimental vs. predicted values in absolute terms for Eq. (13).

Fig.s 7and 8 indicate that the proposed formulations have high correlation coefficient which demonstrates the models have the ability of output parameter well. Also it can be observed from Figs. 9, 10 and Table 2 that the GEP models (Eqs. 12 and 13) predict the target values to an acceptable degree of accuracy and with a relative level of straightforwardness.

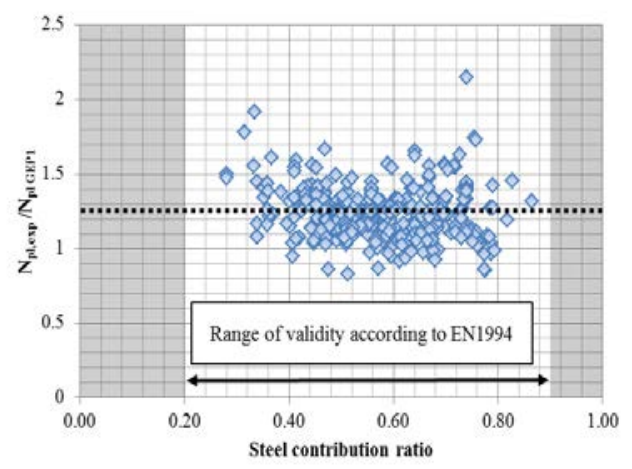

Fig. 9. Experimental results vs. predictions proposed (Eq. 12).

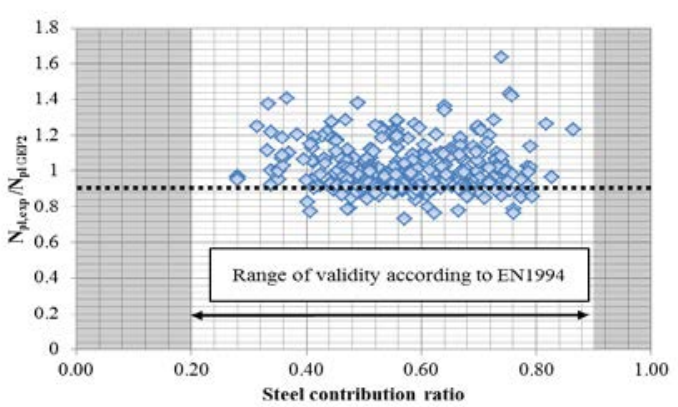

Fig. 10. Experimental results vs. predictions proposed (Eq. 13).

It is worth pointing out from Table 1 that the results obtained provide similar statistical values (mean and variations) to the most suitable mechanically-based formulations (namely, [1]). The percentage of values in which the predicted resistance is greater than the experimentally obtained value is considerably lower than the present EN1994 formulation which includes a certain level of confinement. This value is comparable in magnitude to the one obtained when comparing the experimental prototypes with [1].

On the other hand, the precision of the prediction performance provided by all models is measured using statistical analysis. In fact, the quality of the prediction can generally be characterized by the correlation coefficient $(R)$, route mean square error (RMSE), mean absolute error (MAE), mean square error (MSE) and mean absolute percentage error (MAPE) of the predicted values from the real measured data which given in the form of formulas as follows:

$$
R=\frac{\sum_{i=1}^{N}\left(A_{i}-\bar{A}_{i}\right)\left(P_{i}-\bar{P}_{i}\right)}{\sqrt{\sum_{i=1}^{N}\left(A_{i}-\bar{A}_{i}\right)^{2} \sum_{i=1}^{N}\left(P_{i}-\bar{P}_{i}\right)^{2}}}
$$




$$
\begin{aligned}
& R M S E=\sqrt{\frac{1}{N} \sum_{i=1}^{N}\left(A_{i}-P_{i}\right)^{2}} \\
& M A E=\frac{1}{N} \sum_{i=1}^{N}\left|A_{i}-P_{i}\right| \\
& M S E=\frac{1}{N} \sum_{i=1}^{N}\left(A_{i}-P_{i}\right)^{2} \\
& M A P E=\frac{1}{N} \sum_{i=1}^{N}\left|\frac{A_{i}-P_{i}}{A_{i}}\right| \times 100
\end{aligned}
$$

where $A_{i}$ and $P_{i}$ are respectively the actual and predicted outputs for the ith output, $\bar{A}_{\mathrm{i}}$ and $\bar{P}_{\mathrm{i}}$ are the average of the actual and predicted outputs, and $N$ is the number of sample. Comparing the performance of the GEP-based formulations (Table 3), it can be observed that Eq. (13) has the best performance on the whole of data. Despite of the better performance of the Eq. (13) model, it is slightly complex and has long expressions. Therefore, another GEP-based formulation (Eq. (12)) can be easily employed for prediction of ultimate load in CFTs.

Table 3. Overall performance of the formulas for the ultimate load prediction

\begin{tabular}{l|l|l|l|l|ll}
\hline Model & $\mathrm{R}$ & RMSE & MAE & MSE & MAPE & depict the passive confinement of the concrete core \\
\hline EN1994-Conf & 0.9849 & 260.0076 & 157.3238 & 67603.96 & 9.5584 & due to the presence of the steel tube, which is a \\
\hline $\begin{array}{l}\text { EN1994-No } \\
\text { Conf }\end{array}$ & 0.9843 & 567.4548 & 375.282 & 322004.99 & 21.2112 & drawback of the expression from the phenomenolog- \\
\hline [1] & 0.9844 & 522.1346 & 337.5239 & 272624.53 & 18.9202 & ical point of view. In any case, due to its simple yet \\
\hline [2] & 0.9829 & 276.5112 & 184.5063 & 76458.463 & 11.2205 & statistically robust application, the proposed expres- \\
\hline [3] & 0.9849 & 384.17 & 229.5456 & 147586.57 & 12.6933 & sion may be used for comparison, further study and \\
\hline $\begin{array}{l}\text { Proposed Eq. } \\
\text { Proposed Eq. } \\
\text { (13) }\end{array}$ & 0.9851 & 459.2714 & 311.0689 & 210930.22 & 18.3122 & calibration of the ultimate load capacity of CFT sub-
\end{tabular}
jected to compressive forces.

\section{Conclusions}

The cross-sectional resistance of stocky CFT has been studied quite extensively in last decades. In particular, several mechanically based predictions of the ultimate load capacity to pure compression have been proposed with various levels of accuracy. In this paper, prediction models with mechanical backgrounds as well as ultimate loads provided in EN1994 are compared to a set of 344 experimental tests. The studied formulations include explicitly the level of passive confinement in the core but differ both qualitatively and quantitatively when studying the ultimate load capacity of CFT. On the other hand, the studied models, though mechanically derived, include empirically obtained calibrations to some extent.

In this paper, for the sake of contributing to the field, simple though straightforward formulas aimed at predicting the cross-sectional capacity of CFT are of applying a gene expression programming (GEP) technique (WARNING deleted sentence). In statistical terms, the formulas provide a satisfactory prediction with high level of accuracy. From the design perspective, the equations provide improved results when compared to other existing predictions as well as to EN1994. As a limitation though, it is worth pointing out that these expressions do not explicitly depict the passive confinement of the concrete core due to the presence of the steel tube, which is a proposed. These Eqs. $(12,13)$ are obtained by means 


\section{References}

[1] M. Johansson, The efficiency of passive confinement in CFT columns, Steel Compos. Struct. 2 (2002) 379-396.

[2] K.A.S. Susantha, H. Ge, T. Usami, A capacity prediction procedure for concrete-filled steel columns, J. Earthq. Eng. 5(4) (2001) 483-520.

[3] G.D. Hatzigeorgiou, Numerical model for the behavior and capacity of circular CFT columns, Part I: Theory, Eng. Struct. 30(6) (2008) 1573-1578.

[4] R. Chacón, E. Mirambell, E. Real, Resistance of concrete-filled tubular structures (CFT) on integral bridges, Inf. Constr. 64(527) (2012) 355-370.

[5] Bradford Centre for Sustainable Environments (http://www.bradford.ac.uk/research/rktcentres/centre-for-sustainableenvironments/associationforsteelconcretecompositestructures/columnsdatabase/) (2014).

[6] J. Hajjar, B. Gourley, C. Tort, M. Denavit, P. Schiller, Steel-Concrete Composite Structural Systems, Department of Civil and Environmental Engineering, Northeastern University (2013).

[7] F. Zhou, W. Xu, Cyclic loading tests on concretefilled double-skin (SHS outer and CHS inner) stainless steel tubular beam-columns, Eng. Struct. 127 (2016) 304-318.

[8] H.J. Kim, J.W. Hu, W.S. Hwang, Cyclic testing for structural detail improvement of CFT columnfoundation connections, Sustain. 7(5) (2015) 52605281.

[9] J.W. Hu, W.S. Hwang, Design and behavior of recentering beam-to-CFT column connections with super-elastic shape memory alloy fasteners, Int. J. Steel Struct. 13(1) (2013) 55-69.
[10] J.W. Hu, R.T. Leon, Analyses and evaluations for composite-moment frames with SMA PR-CFT connections, Nonlin. Dyn. 65(4) (2011) 433-455.

[11] J.W. Hu, E. Choi, R.T. Leon, Design, analysis and application of innovative composite PR connections between steel beams and CFT columns, Smart Mater. Struct. 20(2) (2011).

[12] J.W. Hu, J. Park, R.T. Leon, Advanced analysis and performance based evaluation of concrte filled tube (CFT) columns, Adv. Steel Constr. 6(4) (2010) 1019-1033.

[13] C. Ferreira, Gene expression programming: A new adaptive algorithm for solving problems, Complex Syst. 13(2) (2001) 87-129.

[14] C. Ferreira, Gene expression programming: Mathematical Modeling by an Artificial Intelligence, 2 ed., Springer, Germany, 2006.

[15] C. Ferreira, Designing neural networks using gene expression programming, Advances in Soft Computing, 2006, pp. 517-535.

[16] E.A. Colbourn, S.J. Roskilly, R.C. Rowe, P. York, Modelling formulations using gene expression programming - A comparative analysis with artificial neural networks, Eur. J. Pharm. Sci. 44(3) (2011) 366374.

[17] A.H. Gandomi, A.H. Alavi, S. Kazemi, M. Gandomi, Formulation of shear strength of slender RC beams using gene expression programming, part I: Without shear reinforcement, Autom. Constr. 42 (2014) 112-121.

[18] E.M. Güneyisi, M. D'Aniello, R. Landolfo, K. Mermerdaş, A novel formulation of the flexural overstrength factor for steel beams, J. Constr. Steel Res. 90 (2013) 60-71.

[19] A.H. Gandomi, S.K. Babanajad, A.H. Alavi, Y. Farnam, Novel approach to strength modeling of 
concrete under triaxial compression, J. Mater. Civil Eng. 24(9) (2012) 1132-1143.

[20] F.E. Richart, A. Brandtzaeg, R.L. Brown, A study of the failure of concrete under combined compressive stresses, A Study of the Failure of Concrete under Combined Compressive Stresses (1928).

[21] N.J. Gardner, E.R. Jacobson, Structural behavior of concrete filled steel tubes, ACI J. 64(7) (1967) 404413.

[22] W.L.A. de Oliveira, S. De Nardin, A.L.H. de Cresce El Debs, M.K. El Debs, Influence of concrete strength and length/diameter on the axial capacity of CFT columns, J. Construct. Steel Res. 65(12) (2009) 2103-2110.

[23] A.T. Beck, W.L.A. de Oliveira, S. De Nardim, A.L.H.C. ElDebs, Reliability-based evaluation of design code provisions for circular concrete-filled steel columns, Eng. Struct. 31(10) (2009) 2299-2308.

[24] A. Kuranovas, D. Goode, A.K. Kvedaras, S. Zhong, Load-bearing capacity of concrete-filled steel columns, J. Civil Eng. Manage. 15(1) (2009) 21-33.

[25] R. Chacón, E. Mirambell, E. Real, Strength and ductility of concrete-filled tubular piers of integral bridges, Eng. Struct. 46 (2013) 234-246.

[26] B. Evirgen, A. Tuncan, K. Taskin, Structural behavior of concrete filled steel tubular sections (CFT/CFSt) under axial compression, Thin-Wall. Struct. 80 (2014) 46-56.

[27] Z.-H. Lu, Y.-G. Zhao, Suggested empirical models for the axial capacity of circular CFT stub columns, J. Constr. Steel Res. 66(6) (2010) 850-862.

[28] J.R. Koza, Genetic Programming: On the Programming of Computers by Means of Natural Selection, Cambridge: MIT Press1992.

[29] Y. Pan, J. Jiang, R. Wang, H. Cao, Y. Cui, A novel QSPR model for prediction of lower flammability limits of organic compounds based on support vector machine, J. Hazard. Mater. 168(2-3) (2009) 962-969.

[30] M. Đurasević, D. Jakobović, K. Knežević, Adaptive scheduling on unrelated machines with genetic programming, Appl. Soft Comput. 48 (2016) 419-430.

[31] Design of composite steel and concrete structures. Part 1: General rules and rules for buildings, Design of Composite Steel and Concrete Structures (1994).

[32] A. Aytek, O. Kisi, A. Guven, A genetic programming technique for lake level modeling, Hydrol. Res. 45(4-5) (2014) 529-539. 
